\begin{tabular}{l|c|c}
\hline \hline Vol. 31(1):111-119 & Ocean and Polar Research & March 2009 \\
\hline \hline
\end{tabular}

\title{
Note
}

\section{Remote Sensing of Surface Films as a Tool for the Study of Oceanic Dynamic Processes}

\author{
Leonid Mitnik*, Vyacheslav Dubina, Oleg Konstantinov, \\ Vitaly Fischenko, and Denis Darkin \\ V.I. Il'ichev Pacific Oceanological Institute, Far Eastern Branch \\ Russian Academy of Sciences, Vladivostok 690041, Russia
}

\begin{abstract}
Biogenic surface films, which are often present in coastal areas, may enhance the signatures of hydrodynamic processes in microwave, optical, and infrared imagery. We analyzed ERS-1/2 Synthetic Aperture Radar (SAR) and Envisat Advanced Synthetic Aperture Radar (ASAR) images taken over the Japan/East Sea (JES). We focused on the appearance of the contrast SAR signatures, particularly the dark features of different scales caused by various oceanic and atmospheric phenomena. Spiral eddies of different scales were detected through surface film patterns both near the coast and in the open regions of the JES in warm and cold seasons. During field experiments carried out at the Pacific Oceanological Institute (POI) Marine Station 'Cape Shults' in Peter the Great Bay, the sea surface roughness characteristics were measured during the day and night using a developed polarization spectrophotometer and various digital cameras and systems of floats. The velocity of natural and artificial slicks was estimated using video and ADCP time series of tracers deployed on the sea surface. The slopes of gravity-capillary wave power spectra varied between -4 and -5 . Surface currents in the natural and artificial slicks increased with the distance from the coast, varying between 4 and $40 \mathrm{~cm} / \mathrm{s}$. The contrast of biogenic and anthropogenic slicks detected on vertical and horizontal polarization images against the background varied over a wide range. SAR images and ancillary satellite and field data were processed and analyzed using specialized GIS for marine coastal areas.
\end{abstract}

Key words : Envisat ASAR, ERS-2 SAR, grease ice, marine surface films, radar signatures of oceanic phenomena

\section{Introduction}

The Pacific Oceanological Institute (POI) is currently collaborating with the European Space Agency (ESA) in several projects to study dynamic oceanic and atmospheric phenomena using Synthetic Aperture Radar (SAR) images from the ERS-1, ERS-2, and Envisat satellites. The spatial resolution of SAR images is in the range of $25-150 \mathrm{~m}$, with a swath width that varies between approximately 70 and $400 \mathrm{~km}$. This combination is unique, allowing the meso-scale and fine-scale features of the surface circulation, oil pollution, and wind field to be determined regardless of the solar illumination and cloud cover (Alpers 1995; Mitnik and Dubina 2005, 2005a, 2006; Jackson and Apel

*Corresponding author. E-mail : mitnik@poi.dvo.ru
2004). However, the interpretation of SAR signatures is not straightforward because the imprints of oceanic and atmospheric phenomena are frequently superimposed on the images. This problem has greatly hindered the development of automatic and semiautomatic techniques for SAR signature interpretation. However, the reliability of interpretations has been increased by the joint analysis of SAR images with Aqua and Terra MODIS images, satellite-derived sea surface temperature (SST), chlorophyll$a$ and wind fields, and in situ data.

Biogenic and anthropogenic films are often present on the ocean surface and may enhance manifestations of the oceanic dynamic processes in remote sensing data. Sea slicks caused by films look like dark lines, strips, or patches on SAR images because of the damping effect of the film on the backscattered signals from the radar 
instrument. They are formed by surface-active organic compounds that consist of a hydrophobic and a hydrophilic part (Hühnerfuss 2006) and can have either a biogenic (secreted by plankton or fish) or man-made origin.

\section{Data}

There are more than 500 high-resolution SAR images of the Asian marginal seas in the POI database. Additionally, the database contains several thousand so-called quicklook images (QL), which have reduced spatial and radiometric resolution, but still give a good guide to the spatial and temporal distribution of the meso-scale features. The brightness of a SAR image is proportional to the Normalized Radar Cross Section (NRCS), $\sigma^{\circ}$, which in turn is determined by the sea surface roughness (Jackson and Apel 2004).

Here, the $\sigma^{\circ}$ values for horizontal $(\mathrm{H})$ and vertical $(\mathrm{V})$ polarization were computed in $100 \times 100 \mathrm{~m}$ regions for each ASAR/SAR image using the BEST tool (http:// envisat.esa.int/services/best/). The values of $\sigma_{\mathrm{HH}}^{\circ}$ and $\sigma_{\mathrm{VV}}^{\mathrm{o}}$ (Table 1) were computed from $1 \times 1 \mathrm{~km}$ areas with uniform brightness near Cape Shults. Data from other satellite sensors were also available for analysis. They included visible and infrared (IR) images acquired by the
MODIS spectroradiometer and AVHRR radiometer, brightness temperature fields acquired by the Aqua Advanced Microwave Scanning Radiometers AMSR-E, satellite-derived maps of SST, surface wind and chlorophyll- $a$ concentration fields, and weather maps.

Ground-truth measurements were carried out at Cape Shults, Popov Island in Peter the Great Bay, and several other coastal and island points before, during, and after Envisat and ERS-2 overpasses. The acquisition of meteorological characteristics and water temperature at Cape Shults was performed from a pier, a coastal vantage point, and a yacht. Sea surface roughness characteristics were measured using a system of light floats, some single float and calibration spheres, and a developed polarization spectrophotometer (Cape Shults station only). Artificial slicks were also produced using oleic acid and sunflower oil in Vityaz' Bay and in the open sea to the south of Cape Shults. The development of the artificial slicks was studied using video and digital cameras and calibration floats.

The satellite name, date, and time of acquisition, incidence angle $\theta$ of the Cape Shults region, in situ data near Cape Shults (wind vector and air sea temperature difference, $\Delta T_{\mathrm{as}}=T_{\mathrm{a}}-T_{\mathrm{s}}$, where $T_{\mathrm{a}}$ is air temperature near the sea surface and $T_{\mathrm{s}}$ is sea surface temperature), and values of the NRCS at V- and H-polarizations $\sigma_{\mathrm{VV}}^{\mathrm{o}}$ and

Table 1. List of Envisat ASAR and ERS-2 SAR images acquired over Peter the Great Bay

\begin{tabular}{|c|c|c|c|c|c|c|c|c|}
\hline SAR product & Date & $\begin{array}{l}\text { Time } \\
\text { (UTC) }\end{array}$ & $\begin{array}{c}\text { Wind speed } \\
(\mathrm{m} / \mathrm{s})\end{array}$ & $\begin{array}{c}\text { Wind direction } \\
\text { (deg) }\end{array}$ & $\begin{array}{c}\theta \\
(\mathrm{deg})\end{array}$ & $\begin{array}{l}\Delta T_{\text {as }} \\
\left({ }^{\circ} \mathrm{C}\right)\end{array}$ & $\begin{array}{l}\sigma_{\mathrm{Vv}}^{\mathrm{o}} \\
(\mathrm{dB})\end{array}$ & $\begin{array}{l}\sigma_{\text {HH }}^{o} \\
(d B)\end{array}$ \\
\hline ASAR APP & 20 Sep 03 & $01: 33$ & $3.0-5.0$ & 310 & 21.7 & -2.8 & -5.8 & -6.4 \\
\hline ASAR APP & 6 May 04 & $01: 36$ & $6.0-7.0$ & 180 & 17.5 & 5.0 & -0.5 & -2.0 \\
\hline ASAR APP & 12 Jul 04 & $01: 30$ & $3.5-4.0$ & 135 & 25.8 & 0.3 & -10.3 & -13.1 \\
\hline ASAR APP & $15 \mathrm{Jul} 04$ & $01: 36$ & $3.0-3.5$ & 225 & 17.5 & 0.3 & -6.6 & -8.8 \\
\hline ASAR APP & 20 Sep 04 & $01: 30$ & $3.0-4.0$ & 320 & 25.8 & -2.9 & -12.4 & -14.9 \\
\hline SAR PRI & 20 Sep 04 & $01: 59$ & 3.0 & 300 & 26.0 & -2.1 & -6.3 & \\
\hline ASAR APP & 23 Sep 04 & $01: 36$ & $2.0-3.0$ & 315 & 17.5 & -2.9 & -4.0 & -5.3 \\
\hline ASAR APP & 23 Sep 04 & $12: 54$ & 4.0 & 180 & 15.9 & -2.0 & -1.1 & -1.9 \\
\hline SAR PRI & 3 Jan 05 & $01: 59$ & 6.0 & 240 & 26.0 & -6.0 & -9.1 & \\
\hline ASAR APP & 10 Feb 05 & $12: 54$ & 9.0 & 315 & 15.9 & 11.8 & 3.2 & 2.3 \\
\hline ASAR APP & 26 Feb 05 & $01: 33$ & 6.0 & 315 & 21.7 & -3.8 & -3.8 & -4.9 \\
\hline ASAR APP & 16 Jul 05 & $01: 33$ & $0.0-3.0$ & 270 & 21.7 & 2.5 & -13.3 & -16.7 \\
\hline ASAR APP & $26 \mathrm{Jul} 05$ & $01: 19$ & $0.0-3.0$ & 180 & 39.9 & 1.8 & -19.0 & -22.7 \\
\hline ASAR APP & 29 Jul 05 & $01: 25$ & 6.0 & 45 & 33.3 & 2.2 & -16.3 & -19.7 \\
\hline ASAR APP & 02 Sep 05 & $01: 25$ & 4.0 & 270 & 33.3 & -4.0 & -12.0 & -15.5 \\
\hline ASAR APP & 05 Sep 05 & $01: 30$ & 2.0 & 315 & 25.8 & -3.2 & -14.0 & -15.3 \\
\hline ASAR APP & 21 Sep 05 & $01: 27$ & 6.0 & 45 & 29.6 & -4.2 & -13.4 & -16.5 \\
\hline ASAR APP & 07 Oct 05 & $01: 25$ & 1.0 & 180 & 33.3 & -3.0 & -16.9 & -19.3 \\
\hline ASAR APP & 10 Oct 05 & $01: 30$ & $1.0-4.0$ & 45 & 25.8 & -3.4 & -14.0 & -16.9 \\
\hline
\end{tabular}


$\sigma_{\mathrm{HH}}^{\mathrm{o}}$ to the south of Cape Shults were determined for each image analyzed (Table 1). The local time was equal to Greenwich time plus $10 \mathrm{~h}$.

\section{Results}

\section{Eddies in Peter the Great Bay}

Our analysis of the ERS-2 SAR and Envisat ASAR images of the Japan/East Sea focused on the properties of the SAR signatures. Of particular interest were the dark features of different scales, which were caused by natural (biogenic) slicks, oil spills, and grease ice. Both biogenic and anthropogenic films were detected on all analyzed SAR images of the JES. To improve the interpretation of SAR signatures, ground truth observations were carried out at POI Marine Stations Popov Island and Cape Shults in 2004-2006. Slick patches and bands were often observed in SAR images taken over Peter the Great Bay.

On 16 July 2005, oceanic eddy motion was presumably responsible for collecting surfactants into the curved and spiral patterns observed (Fig. 1). The abundance of surfactant material was most likely due to blooms of algae and other plankton, which release hydrophobic oils into the environment (Hühnerfuss 2006). A region of low wind at the bottom right of the image hindered the detection of the slick. The wind speed $W$ recorded close to the time of acquisition was 10 knots from the north. An anticyclonic meander of scale $\approx 25 \mathrm{~km}$ was located south of Big Pelis Island between the 50-m and 100-m isobaths (Fig. 2). This feature is clearly visible in the SAR image; the spiral-shaped lines associated with small-scale turbulence are aligned in the direction of the larger-scale eddy motion.

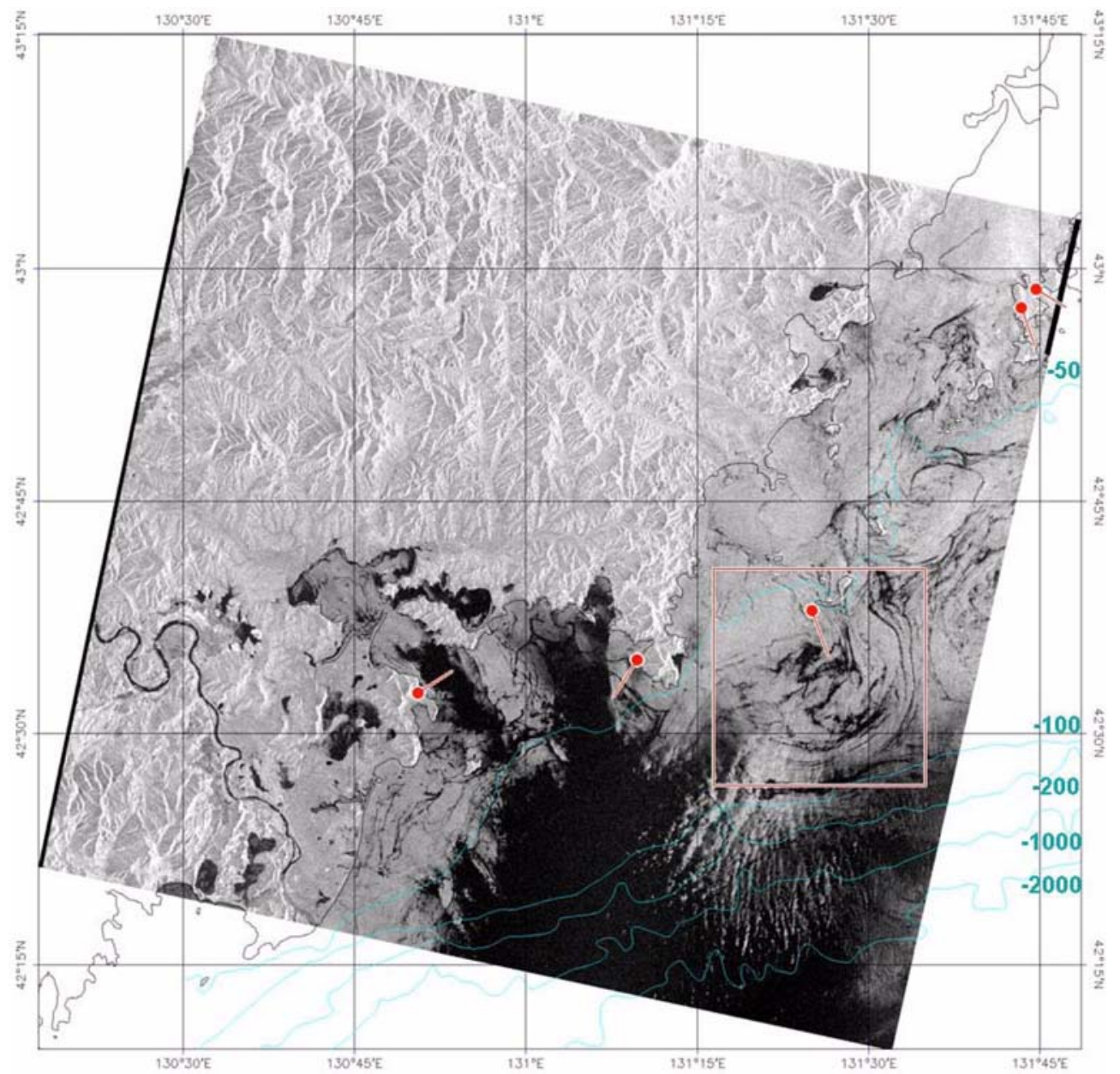

Fig. 1. Envisat ASAR image of Peter the Great Bay taken on 16 July 2005 at 01:33 UTC, showing eddy structures and spirals formed by natural films in the presence of light winds $(W=2-5 \mathrm{~m} / \mathrm{s})$. The dark area at the bottom right is due to the absence of small-scale roughness at $W<2-3 \mathrm{~m} / \mathrm{s}$. Blue lines indicate depth contours. Red dots indicate points where the wind speed was measured. The red box marks the boundaries of the fragment enlarged in Fig. 2. 


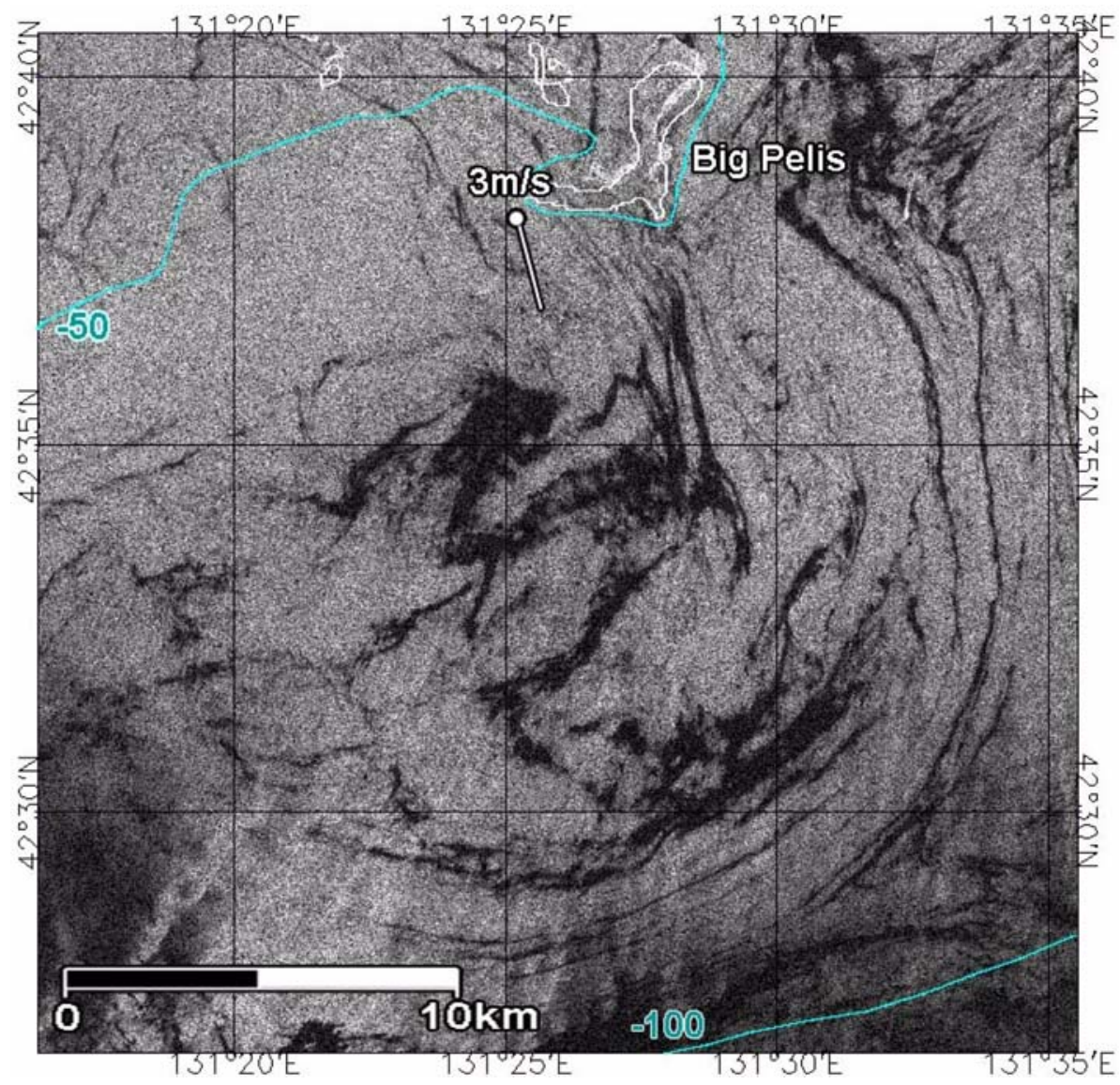

Fig. 2. Fragment of an Envisat ASAR image taken on 16 July 2005 at 01:33 UTC, showing an anticyclonic meander in Peter the Great Bay.

Small-scale turbulence leads to convective motion in the water, which can bring organic material present in the upper layer to the surface. There, it may remain as a microlayer of natural surface film, which inhibits the growth of capillary and short gravity waves.

The spiraling lines suggest a convergence of fluid toward the eddy center, which in turn suggests that this cyclonic eddy may have been locally important for the distribution and concentration of chlorophyll- $a$, algae, and pollutants such as oil spills. Typical synoptic-scale eddies in the subarctic frontal zone of the JES and other areas are known to be especially important in this regard. Because the small-scale surface roughness was low, the surface radar echo was weak, leading to low backscatter dark features from surface slicks (e.g., Fig. 1). The dark spiral lines were expected to disappear for $\mathrm{W}>6-7 \mathrm{~m} / \mathrm{s}$ because the wind-induced mixing in the upper layer would then redistribute the surface slicks, preventing the radar damping effect.

At wind speeds $<5-6 \mathrm{~m} / \mathrm{s}$, biogenic slicks act as tracers for the meso-scale and submeso-scale features of surface circulation such as westward water flow, spiral eddies, and chains of eddies of different scales (Fig. 3). Large dark patches mark the areas where the wind speed was lower than the threshold value needed for the generation of centimeter-scale surface waves. Slicks were present both in the coastal areas, where the depth is $\leq 100 \mathrm{~m}$, and in the open sea, where the depth is $>1000 \mathrm{~m}$ (Fig. 3). Spiral eddies were the main feature of surface circulation, indicating that spirals were a competitive form of water movement over a broad range of water depths.

\section{Optical Measurements of Sea Surface Roughness}

Measurements of the sea surface slope distribution and the mean-square slope in the field experiments are important for the interpretation of SAR signatures. Techniques based on light reflection ('shape from reflection') are well established as a way of acquiring wave slope images; as has been shown previously, they are accurate enough to allow the computation of two-dimensional wave number spectra. Standard optical devices (video cameras, polarization spectrophotometers) and techniques have been 


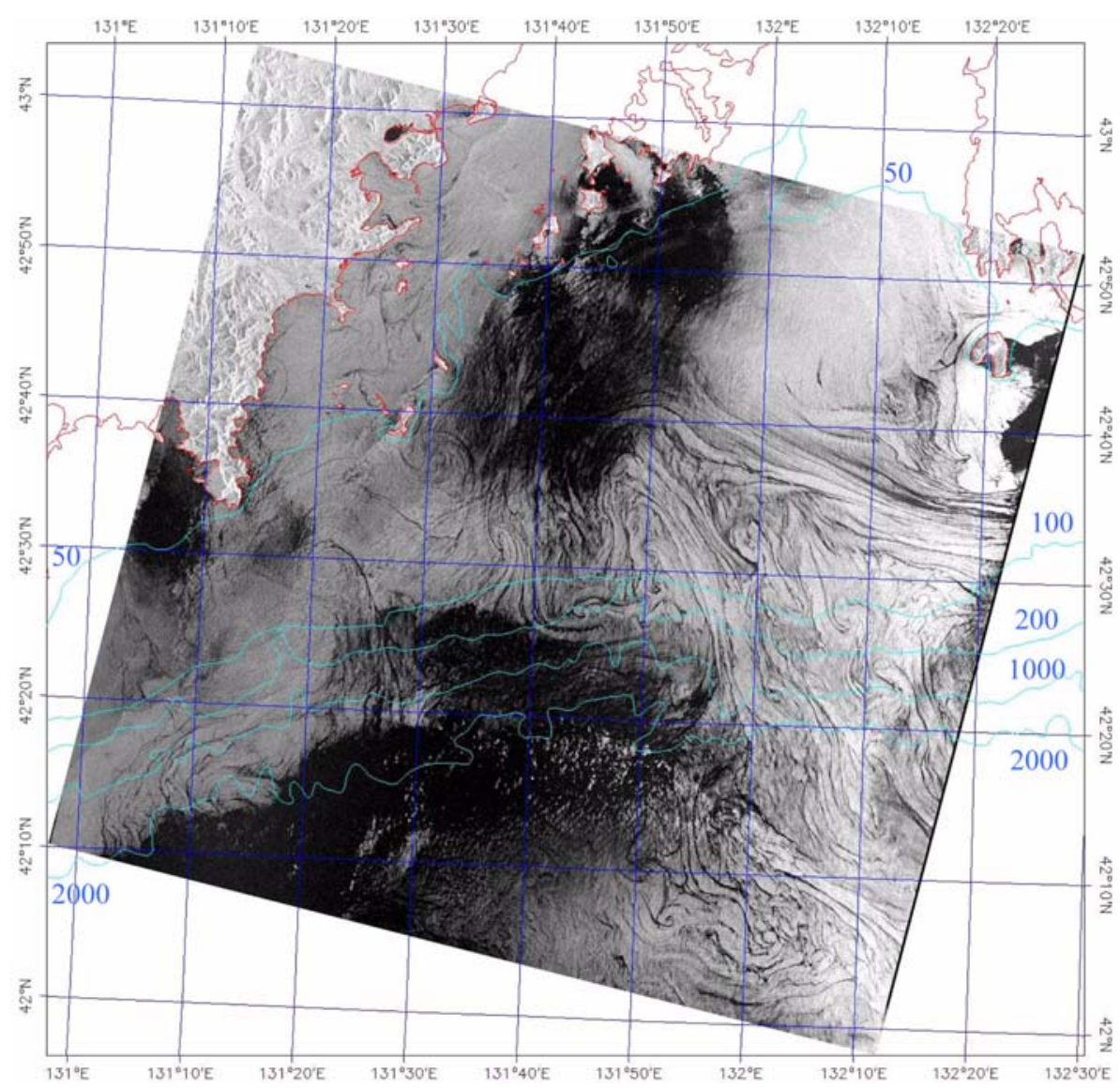

Fig. 3. Envisat ASAR image of Peter the Great Bay taken on 5 September 2005 at 01:30 UTC. The filamentary slicks show numerous organized structures, clearly visualizing the sea surface circulation. Blue lines indicate depth contours.

used to derive the characteristics of gravity and gravitycapillary waves under a range of environmental conditions, in particular during observations by the ERS-2 SAR and Envisat ASAR instruments (Konstantinov 2005).

The characteristics of sea surface roughness were calculated from a time series of the brightness variations of a light white disk floating on the sea surface. The disk effectively acted as a filter for the surface waves. Roughness characteristics were also calculated from the brightness variations of sea surface images recorded at three polarizations with frequencies of 6-50 Hz. All processing was performed using original software.

Oleic acid and sunflower oil were poured from a boat during ERS-2 and Envisat sensing to produce patches and narrow bands of artificial slicks. Both these and natural biogenic slicks in Vityaz' Bay and the open Japan/East Sea were then recorded by video cameras and a digital photo camera from the coast. The slicks were simultaneously detected from space by the Envisat ASAR instrument (Fig. 4).
Panoramic video images were transformed into planar coordinates to allow direct comparison with the planar satellite SAR images. Slicks on the radar images (Fig. 4b) appeared as dark features against the background waters. In the visible images (Fig. 4a), in contrast, they could appear both brighter than the background (e.g., artificial slick, 4, and the left side of the spiral eddy, 5, in sun glint area) and darker than the background (right side of the eddy, 5, beyond sun glint area). The slope of the gravitycapillary wave power spectrum changed between -4 and -5 (Mitnik et al. 2006). Surface currents in the slickcovered areas were estimated via observations of tracers (small contrast floats). The currents increased with the distance from the coast, varying between 4 and $40 \mathrm{~cm} / \mathrm{s}$. The contrast of the biogenic and anthropogenic slicks detected on VV- and HH-polarization images against the background varied over a broad range. The polarization ratio $\mathrm{VV} / \mathrm{HH}(\mathrm{PR})$ was calculated both in regions covered by surface films and in those containing surface imprints of oceanic internal waves (the latter were detected via an 


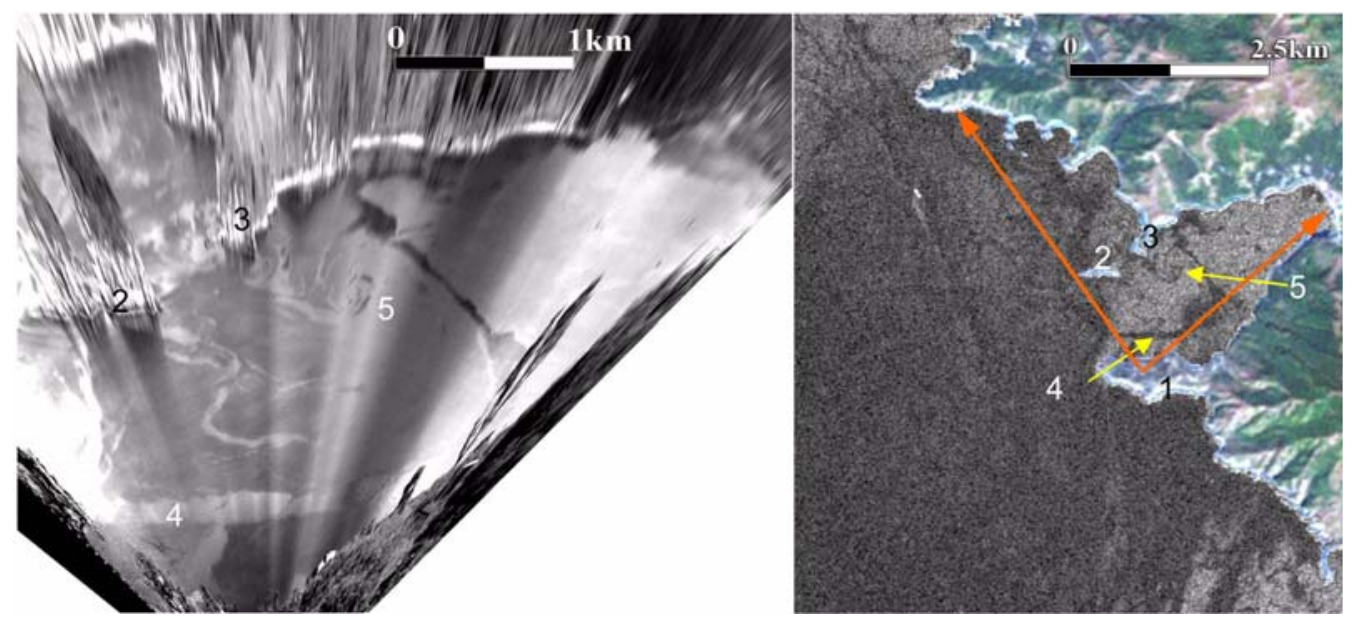

Fig. 4. Simultaneous Envisat ASAR and ground-based optical observations of biogenic and artificial slicks in Vityaz' Bay, taken on 5 September 2005 at 01:30 UTC. (a) Panoramic image obtained with a video camera from Cape Shults (transformed into planar coordinates). (b) Envisat ASAR image fragment: (1) Cape Shults, (2) an island, (3) a cape on the opposite side of Vityaz' Bay, (4) an artificial slick band formed by oleic acid, and (5) a cyclonic slick spiral formed by biogenic film. Red arrows in (b) indicate the boundaries of the panoramic image.

analysis of Envisat images of Peter the Great Bay).

The PR varied with incidence angle $\theta$ from approximately $1.5 \mathrm{~dB}$ at $\theta=14.5-15^{\circ}$ to $2.8 \mathrm{~dB}$ at $\theta=25.5-26^{\circ}$, with a measured wind speed of $W=3-5 \mathrm{~m} / \mathrm{s}$. The theoretical PR is in agreement with the SAR models; however, there are significant changes near the slick edges. Unfortunately, the available data do not allow an assessment of the best VV- or HH-polarization combination for the study of oceanic phenomena at low incidence angle: $\theta$ average values were $18.3^{\circ}$ or $22.5^{\circ}$. However, the influence of calibration errors, pointing accuracy, and polarization isolation on the VV- and HH-polarization data cannot necessarily be neglected.

\section{Grease Ice as Indicator of Oceanic Dynamic Processes} Grease ice, which damps the small-scale sea surface
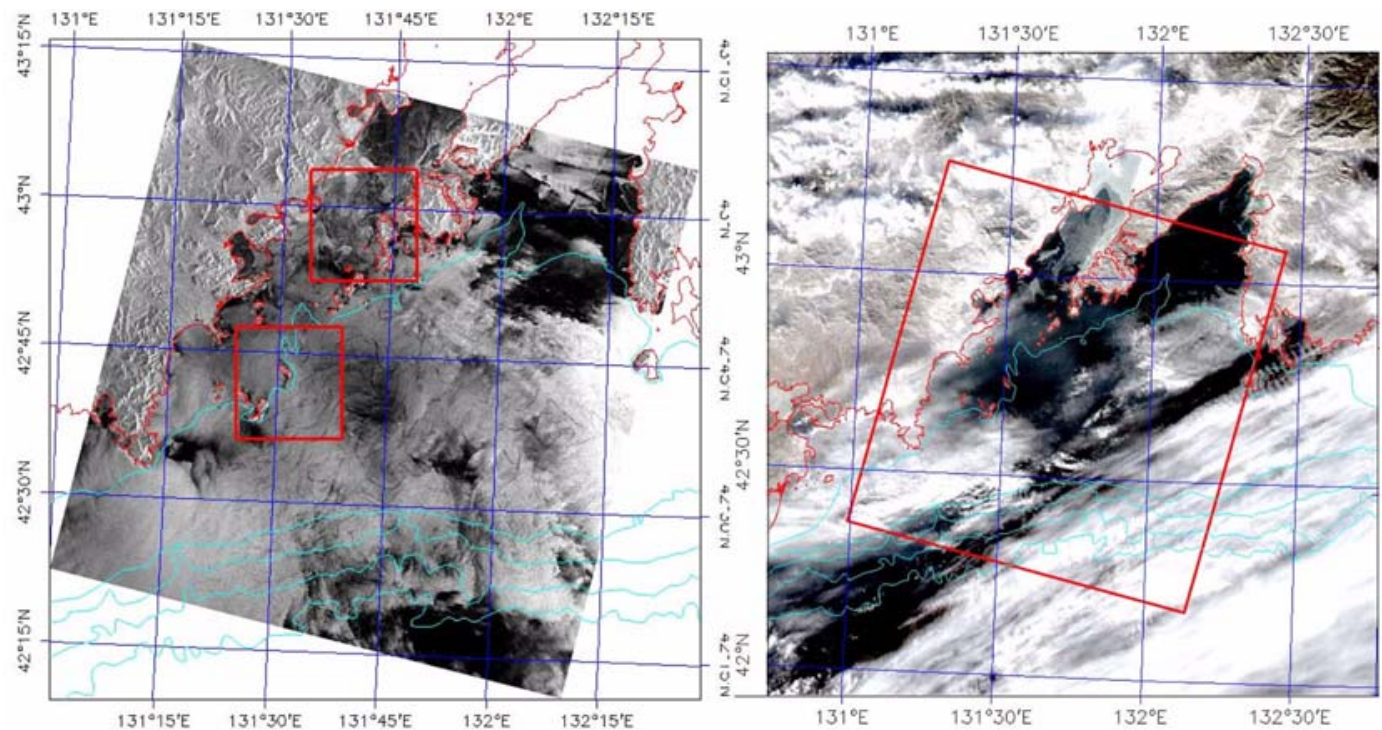

Fig. 5. Images of Peter the Great Bay taken on 3 January 2005 by (a) ERS-2 SAR at 01:59 UTC and (b) Aqua MODIS at 04:15 UTC. Light blue lines are isobaths. The two red boxes in (a) indicate the areas chosen for detailed analysis. The red box in (b) indicates the boundaries of the ERS-2 SAR image. The sea ice in Amursky Bay is clearly visible against the dark open water. 


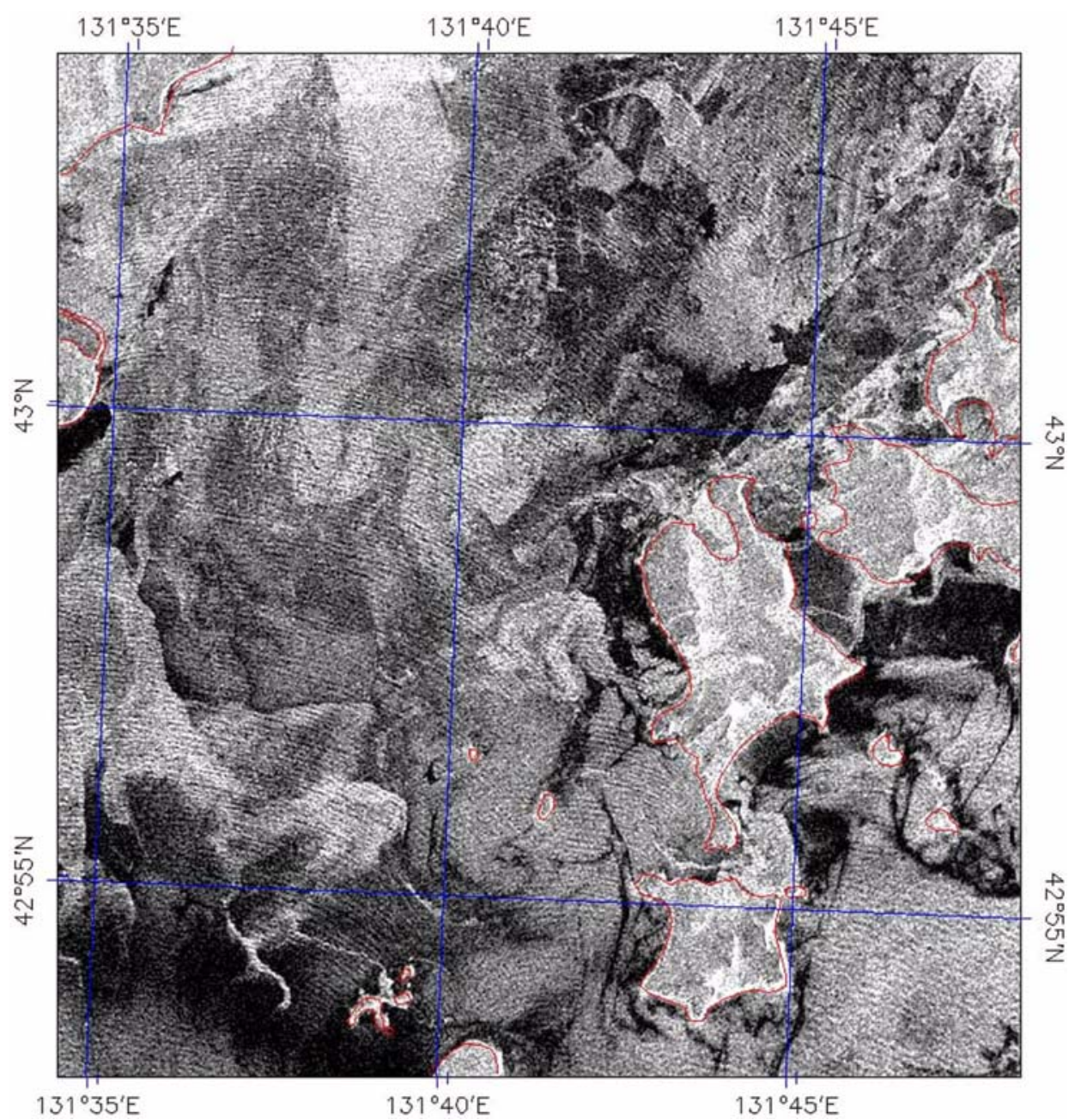

Fig. 6. Fragment 1 of ERS-2 SAR image showing sea ice and swell. Narrow dark bands are most likely filamentary slicks; however, dark features can also be caused by grease ice. The red lines outline the coast and islands.

roughness and thus appears on SAR images as dark bands and patches, is of special interest in winter. It was detected in SAR images of Peter the Great Bay and Tartar Strait. Dark SAR signatures in cold waters can of course also be caused by surface films. Fig. 5 shows an ERS-2 SAR image superimposed on the geographical map, and an Aqua MODIS visible image of the same region. The time separation between the images is approximately $2 \mathrm{~h}$ 15 min. Sea ice in Amursky Bay can be observed in both images. The weather conditions (weak winds and, most likely, swell propagating from the south) were favorable for slick band formation (see Fig. 6).

\section{Eddies in the Open Sea: Multisensor Study}

A combination of SAR, thermal infrared, visible and passive microwave images, QuikSCAT-derived wind fields, and hydrometeorological data were used to study oceanic phenomena in the open sea. The resolution of most satellite images is too coarse to detect slicks (the maximum is $250 \mathrm{~m}$, for the Terra and Aqua MODIS). However, images may still provide estimates of environmental parameters that influence slick appearance and behavior. Several Envisat ASAR and NOAA AVHRR IR images of mesoscale eddies and warm water flows are displayed in Fig. 7. The location of the thermal gradients is strongly correlated with the location of SAR signatures, which are caused by current shifts at the boundaries of synoptic eddies, eddylike features, and frontal zones. The correlation is significantly greater for wind speed $W<10 \mathrm{~m} / \mathrm{s}$.

\section{Slick and Spill-oriented International Projects}

The Distributed Oceanic Research and Information System (DORIS), which is based on Web-GIS technologies, was developed at POI FEB RAS (http://gis.poi.dvo.ru). GIS covers the Northwest Pacific Ocean, including the 

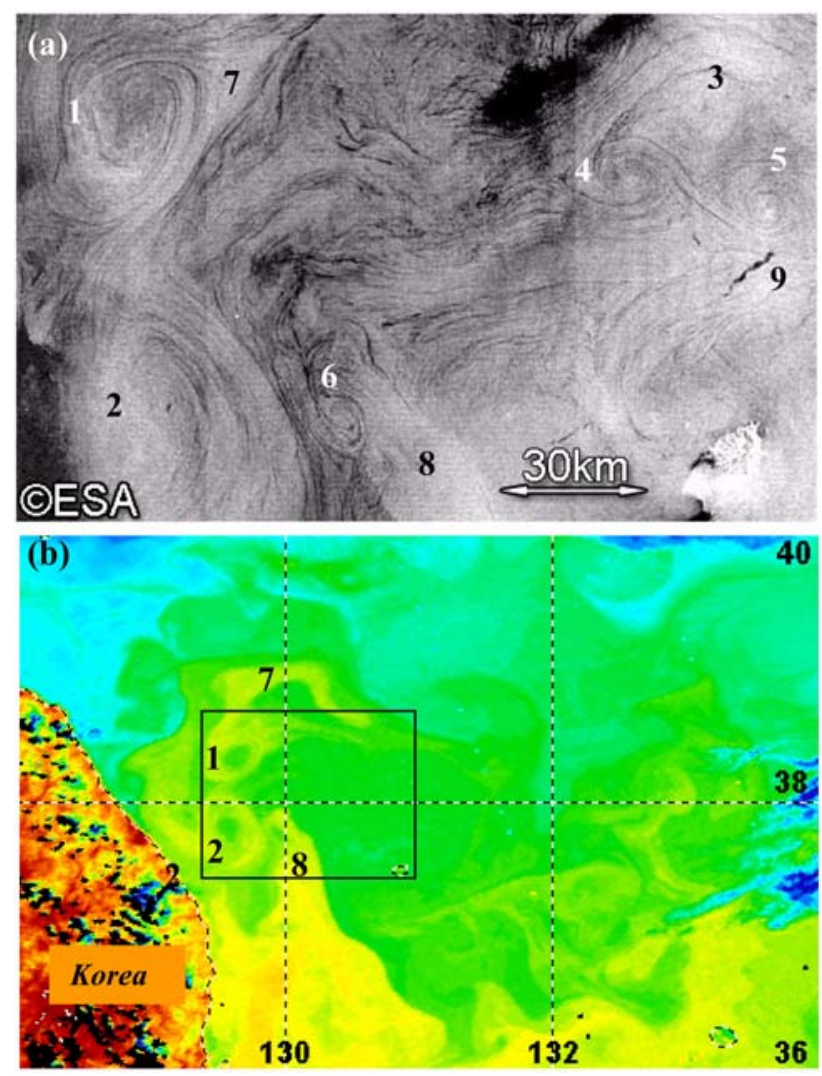

Fig. 7. Cyclonic eddies 1-6, warm water flows 7 and 8, and oil pollution 9 in (a) Envisat ASAR image taken on 14 April 2004 at 01:28 UTC and (b) NOAA AVHRR infrared image taken on 14 April 2004 at 15:20 UTC.

coastal zone of the JES (Golik et al. 2004). Through a web-based interface, GIS provides access to large oceanographic data sets, including satellite data. It also allows simultaneous cartographic visualization of many data types and provides tools for analytical data processing. The DORIS data access policy varies with the user group; specialized portals based on the DORIS tools were developed for several international projects. Two projects associated with the study of marine surface film are of particular interest to specialists in satellite oceanography: INTAS project 03-51-4987 'SIMP: Slicks as Indicators for Marine Processes' (http://simp.poi.dvo.ru) and 'Oil Spill Monitoring by Remote Sensing' (http://cearac.poi.dvo.ru/). The latter project was developed at the POI for the Special Monitoring and Coastal Environmental Assessment Regional Activity Center (CEARAC). CEARAC coordinates activities relevant to specific components of the Action Plan for the Protection, Management, and Development of the Marine and Coastal Environment of the Northwest Pacific Region
(NOWPAP). The NOWPAP is one of the Regional Seas Programs of the United Nations Environments Program (UNEP). Four countries are participants in the program: the Peoples' Republic of China, Japan, the Republic of Korea, and the Russian Federation.

\section{Summary}

Biogenic surface films are often present in coastal waters, but are less common in the open sea. They may form structures which are driven by hydrodynamic phenomena and processes (currents, eddies, plumes, internal waves, etc.). Because they have an influence on the backscattering of microwaves, they may be visible on radar imagery that allows for monitoring of these processes via their surface manifestations. SAR imagery is at the center of the ongoing POI effort to study surface films because of its high resolution and the pronounced effect of surface films on backscattering at microwave frequencies.

We found that dark SAR signatures can serve as fluiddynamical indicators, revealing eddies of various scales on SAR images. The results of SAR signatures analysis showed the advantages of a multisensor approach, particularly in combination with specialized GIS. This gave an increased probability of detecting biogenic slicks against the variable background and against other dark features caused by grease ice and oil spills. A similar approach to that described here could be used to analyze L-band PALSAR images obtained from the Advanced Land Observing Satellite (launched in Japan in 2006). Furthermore, field experiments using new optical devices developed at the POI may give new insights into the physical factors that determine the $\mathrm{C}$ - and L-band radar signatures of biogenic films and oil spills.

\section{Acknowledgements}

This study was presented at the 3rd KORDI-POI workshop, South Sea Institute, KORDI, 2007. We thank the European Space Agency for SAR images provided within ESA ERS project AO3-401, Envisat project AOID-391, and ESA-IAF Bear project AO-2775. This work was partly supported by the RFBR-DVO project 06-0596076-p_vostok_a, a Russian State project "Investigation of ocean-atmosphere system with passive and active microwave sensing from new generation of satellites", and DVO grants 06-1-P16-064 and 07-III-B-07-064. 


\section{References}

Alpers W (1995) Measurement of mesoscale oceanic and atmospheric phenomena by ERS-1 SAR. Radio Sci Bul 275: $14-22$

Golik AV, Fischenko VK, Dubina VA, Mitnik LM (2004) Usage of internet-based GIS of the NW Pacific for joint analysis of satellite and sub-satellite data. In: Proceedings of international symposium on remote sensing ISRS-2004, Jeju, Korea, October 27, pp 371-374

Hühnerfuss H (2006) Basic physicochemical principles of monomolecular sea slicks and crude oil spils. In: Gade M, Huhnerfuss H, Korenowski GM (eds) Marine surface films: chemical characteristics, influence on air-sea interactions and remote sensing. Springer, pp 21-35

Jackson CR, Apel JR (2004) Synthetic aperture radar marine users manual. US Department of Commerce, NOAA/ NESDIS office of research and application, Washington. http://www.sarusersmanual.com/. Accessed 25 Jun 2004

Konstantinov OG (2005) Analysis of the polarizing video images of the sea surface. In: Abstract book of 2nd EARSel workshop on remote sensing of the coastal zone, Porto, Portugal, June 9-11 EARSel, pp 44
Mitnik LM, Dubina VA (2005) Biogenic and anthropogenic slicks on ERS-1/2 SAR and Envisat ASAR images of the Northwest Pacific Region. In: Proceedings of 1st international workshop on HAB in the Northwest Pacific Region, Toyama, Japan, June 30-July 1, CEARAC, pp 117-125

Mitnik LM, Dubina VA (2005a) Synoptic-scale, mesoscale and fine-scale oceanic features in the Japan/East Sea: Study with ERS-1/2 SAR and Envisat ASAR. In: Proceedings of International Geoscience and Remote Sensing Symposium (IGARSS05), Seoul, Korea, July 24-29, pp 4788-4791

Mitnik LM, Dubina VA (2006) Surface currents in the Japan and Okhotsk Seas: study with satellite SAR. In: Proceedings of IGARSS06, Denver, Colorado, USA, July 31 - August 4, pp 2394-2396

Mitnik LM, Dubina VA, Konstantinov OG (2006) Envisat ASAR polarization experiments in the Peter the Great Bay, Japan Sea: preliminary results. EARSel eProceedings 5, pp 199-207 